Research paper

\title{
Polymer "ruthenium-cyclopentadienyl" conjugates - New emerging anti-cancer drugs
}

\author{
Tiago Moreira a, b, Rita Francisco a, b, Elisabeta Comsa ${ }^{c}$, Sophie Duban-Deweer ${ }^{\mathrm{d}}$, \\ Valérie Labas ${ }^{\text {e }}$, Ana-Paula Teixeira-Gomes ${ }^{e}$, Lucie Combes-Soia ${ }^{e}$, Fernanda Marques ${ }^{\mathrm{f}}$, \\ António Matos ${ }^{\mathrm{g}}$, Audrey Favrelle ${ }^{\mathrm{h}}$, Cyril Rousseau ${ }^{\mathrm{i}}$, Philippe Zinck ${ }^{\mathrm{h}}$, Pierre Falson ${ }^{\mathrm{c}}$, \\ M. Helena Garcia ${ }^{a}$, Ana Preto ${ }^{b}$, Andreia Valente ${ }^{a, *}$ \\ ${ }^{a}$ Centro de Química Estrutural, Faculdade de Ciências da Universidade de Lisboa, Campo Grande, 1749-016, Lisboa, Portugal \\ b Centre of Molecular and Environmental Biology (CBMA), Department of Biology, University of Minho, Portugal. Campus de Gualtar, Braga, 4710-057, \\ Portugal \\ ${ }^{c}$ Drug Resistance \& Membrane Proteins Team, Molecular Microbiology and Structural Biochemistry Laboratory, CNRS-UCBL1 UMR 5086, IBCP, 69367, Lyon, \\ France \\ d Laboratoire de la barrière hémato-encéphalique (LBHE), Plateau Spectrométrie de Masse de l'ARTois (SMART), Université d'Artois, EA 2465, Lens, F-62300, \\ France \\ e Plate-forme de Chirurgie et d'Imagerie pour la Recherche et l'Enseignement (CIRE), Pôle d'Analyse et d'Imagerie des Biomolécules (PAIB), PR China, INRA, \\ CNRS, Université de Tours, IFCE, 37380, Nouzilly, France \\ ${ }^{\mathrm{f}}$ Centro de Ciências e Tecnologias Nucleares, Instituto Superior Técnico, Universidade de Lisboa, E.N.10, 2695-066, Bobadela LRS, Portugal \\ ${ }^{g}$ Centro de Investigação Interdisciplinar Egas Moniz, Egas Moniz-Cooperativa de Ensino Superior CRL, Campus Universitário, Quinta da Granja, Monte de \\ Caparica, 2829-511, Caparica, Portugal \\ ${ }^{\mathrm{h}}$ Univ. Lille, CNRS, Centrale Lille, ENSCL, Univ. Artois, UMR 8181 - UCCS - Unité de Catalyse et Chimie du Solide, F-59000, Lille, France \\ ${ }^{\mathrm{i}}$ Unity of Catalysis and Solid State Chemistry, UMR CNRS 8181, University of Artois, 62000, Lens, France
}

\section{A R T I C L E I N F O}

\section{Article history:}

Received 14 November 2018

Received in revised form

21 February 2019

Accepted 21 February 2019

Available online 25 February 2019

\section{Keywords:}

Ruthenium organometallic compounds

Polymer-metal conjugates

Proteomic analysis

Cytoskeleton

\begin{abstract}
A B S T R A C T
In this work, we aimed to understand the biological activity and the mechanism of action of three polymer-'ruthenium-cyclopentadienyl' conjugates (RuPMC) and a low molecular weight parental compound (Ru1) in cancer cells. Several biological assays were performed in ovarian (A2780) and breast (MCF7, MDA-MB-231) human cancer derived cell lines as well as in A2780cis, a cisplatin resistant cancer cell line. Our results show that all compounds have high activity towards cancer cells with low $\mathrm{IC}_{50}$ values in the micromolar range. We observed that all Ru-PMC compounds are mainly found inside the cells, in contrast with the parental low molecular weight compound Ru1 that was mainly found at the membrane. All compounds induced mitochondrial alterations. PMC3 and Ru1 caused F-actin cytoskeleton morphology changes and reduced the clonogenic ability of the cells. The conjugate PMC3 induced apoptosis at low concentrations comparing to cisplatin and could overcame the platinum resistance of A2780cis cancer cells. A proteomic analysis showed that these compounds induce alterations in several cellular proteins which are related to the phenotypic disorders induced by them.

Our results suggest that PMC3 is foreseen as a lead candidate to future studies and acting through a different mechanism of action than cisplatin. Here we established the potential of these Ru compounds as new metallodrugs for cancer chemotherapy.
\end{abstract}

(C) 2019 Elsevier Masson SAS. All rights reserved.

\section{Introduction}

Chemotherapy is one of the basis of cancer therapy although the

\footnotetext{
* Corresponding author.

E-mail address: amvalente@fc.ul.pt (A. Valente).
}

drugs in clinical use present major limitations such as nonselectivity and resistance to therapy which are responsible for serious side effects. In this frame, several new approaches aiming targeted therapy have been developed in the last years taking advantage of the specific characteristics of cancer cells, such as the permeability to macromolecules, acidic extracellular $\mathrm{pH}$, overexpressed cell surface receptors, among others. In the case of 
platinum-based drugs, some of the approaches include the conjugation of platinum drugs with peptides [1-6], receptor-specific ligands [4,7], or polymers [1,8-11], the formulation of nanoparticles [8-10,12-14], or photosensitizers [11], to name a few. Peptides, and receptor-specific ligands conjugates can be used for active targeting, while polymers and nanoparticles are usually applied for passive targeting. Photosensitizers are typically used in photodynamic therapy. The research in this area is very active and the data obtained so far is promising. However, even after many years of development, platinum based anticancer drugs still cause severe side effects.

The search for alternatives pointed out that ruthenium compounds might constitute alternative promising candidates. The first generation of ruthenium drugs, even if very successful, with two inorganic compounds (NAMI-A and KP1019; Fig. 1) completing Phase I clinical trials [15-17], did not lead yet to compounds in the clinic due to limited solubility that hindered dose escalation [18] and also short half-lifes [19]. Fuelled by these results, the area of ruthenium conjugates has greatly expanded in the last years aiming to overcome some of these issues and to increase the selectivity towards cancer cells [20,21]. Several approaches based on dendrimers and dendronized polymers [22,23], coordination-cage $[24,25]$, protein [26,27], nanoparticles [28,29], polymer [30-35] and lipid-based [36] conjugates are being developed. More specifically, since KP1019 has low stability in aqueous solution, especially at physiological $\mathrm{pH}$, poly(lactic acid) (PLA) nanoparticles with Tween 80 have been prepared [37]. The proliferative studies revealed that the nanoparticles increased the activity of KP1019 by about 20 fold, although accompanied by a colour change from brown to green. The authors attributed this variation to a reaction between KP1019 and Tween 80 accompanied by a reduction of the $\mathrm{Ru}$ (III) centre. One advantage of these nanoparticles was the ability of solubilisation of KP1019 at the necessary doses for in vivo application. In relation to NAMI-A two approaches based on the incorporation of copolymers have been adopted. Thus, in order to increase the cytotoxicity and cellular uptake of this drug, a NAMI-Acopolymer conjugate based on poly(4-vinyl imidazole) and poly(ethylene glycol) methyl ether acrylate was designed [38]. In solution this amphiphilic block copolymer is able to self-assemble into micelles. Overall, the cytotoxicity was increased by ca. 1.5 fold in the cancer cells tested (ovarian cancer A2780 and Ovcar-3 and pancreatic AsPC-1 cancer cell lines). However, one cannot neglect the cytotoxicity induced by the poly(4-vinyl imidazole) block. The NAMI-A micelles also seemed to impart a better antimetastatic potential relatively to NAMI-A alone. Nanoparticles based on

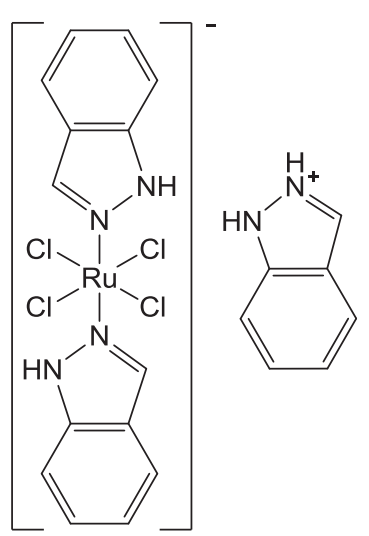

KP1019

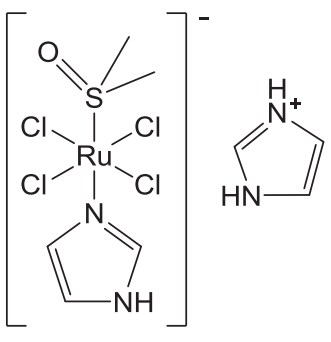

NAMI-A
Fig. 1. Chemical structures of KP1019 and NAMI-A. poly(lactide-co-glycolide) and poly(ethylene-glycol) have been also successfully prepared and tested in vivo in T739 mice implanted with lung cancer line LA795 [39]. The results showed that the NAMI-A-loaded nanoparticles allowed a better antitumor effect, delaying the tumour growth. Altogether, these results show the pertinence of this area of research. In this frame, we have developed a family of polymer "ruthenium-cyclopentadienyl" conjugates (RuPMC) as potential anticancer agents $[40,41]$ bearing an organometallic fragment, with proved cytotoxic activity $[43,44]$ and adequate aqueous stability $[44,45]$, and polylactide chains. Here, we present a detailed study in cancer derived cell lines trying to unravel RuPMCs' biological activity and the possible mode of action. To that purpose, several biological assays namely cellular distribution, analysis of cell morphological alterations, apoptosis analysis, colony formation assay, F-actin structure analysis as well as proteomic studies were performed in different cancer cell lines models.

\section{Results and discussion}

Both polymer-'ruthenium-cyclopentadienyl' conjugates PMC1PMC3 and the low molecular weight parental compound Ru1 were prepared as previously described [40-42] and are presented in Fig. 2. PMC1 and PMC2 were obtained using the same protocol in which for the synthesis of the polylactide macroligand, 2,3,4-tri-Obenzyl- $\alpha$ - $D$-glucopyranoside was used as initiator of lactide's polymerization catalysed by 4-dimethylaminopyridine (DMAP). The resulting product was coupled to 2,2'-bipyridine-4,4'-dicarbonyl dichloride [40]. The synthesis of PMC3 was developed as an alternative to this method in order to achieve full bipyridine functionalization with polylactide (the functionalization used for PMC1 and PMC2 was only about 75\%). In the case of PMC3, the use of $4,4^{\prime}$-diyldimethanol-2,2'-bipyridine as initiator in a DMAP catalysed polymerization allowed the obtention of full bipyridine functionalization, thus no "free" polymer is present in the final product formulation [41]. Ru1 is the non-polymeric version of these compounds [42] and was chosen for these studies in order to assess the influence of the polymeric chain on the overall mode of action of this family of compounds.

\subsection{Determination of compounds $I_{50}$ concentrations}

The $\mathrm{IC}_{50}$ concentration of the compounds was assessed by the cytotoxicity assay MTT in three human cancer cell lines: A2780 ovarian, hormone dependent MCF7 and triple negative MDA-MB231 breast cells. The $\mathrm{IC}_{50}$ values were determined after $72 \mathrm{~h}$ incubation with the complexes within the concentration range $10 \mathrm{nM}-100 \mu \mathrm{M}$ (Table 1 ). All the compounds showed high activity towards the three cancer cells with low $\mathrm{IC}_{50}$ values in the micromolar range and, in most cases, much better than cisplatin.

\subsection{Intracellular distribution of the ruthenium complexes}

The intracellular distribution of the Ru complexes was performed using the MCF7 cells following exposure to each ruthenium complex for $24 \mathrm{~h}, 37^{\circ} \mathrm{C}$ at a concentration equivalent to their $\mathrm{IC}_{50}$ (Table S1). Cytosol, membranes, nucleus and cytoskeletal fractions were extracted using a commercial kit (FractionPREP cell fractionation kit, BioVision) following the manufacturer's protocol. The ruthenium content in the different fractions was measured with a Thermo XSERIES quadrupole ICP-MS instrument (Thermo Scientific) after digestion of the samples. As observed in Fig. 3, Ru was mainly found inside the cells for all polymer-metal conjugates, in contrast with the non-polymeric compound Ru1 that was mainly found (Ru content) in the membrane fraction. These findings are in 


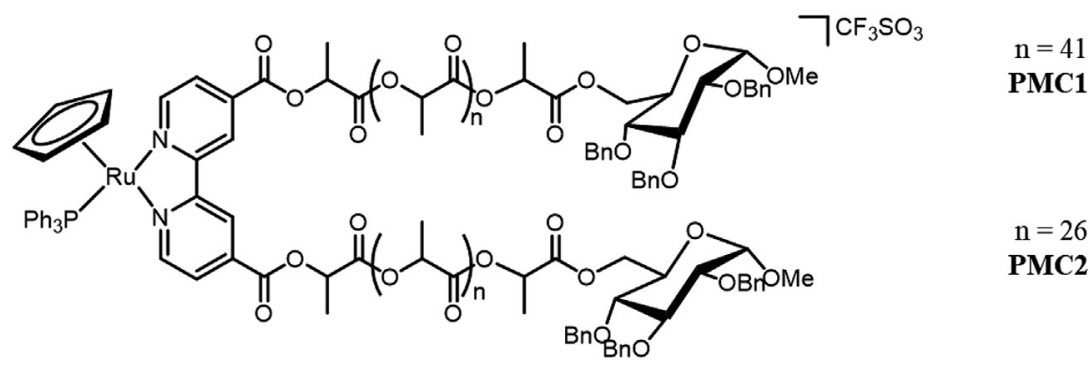

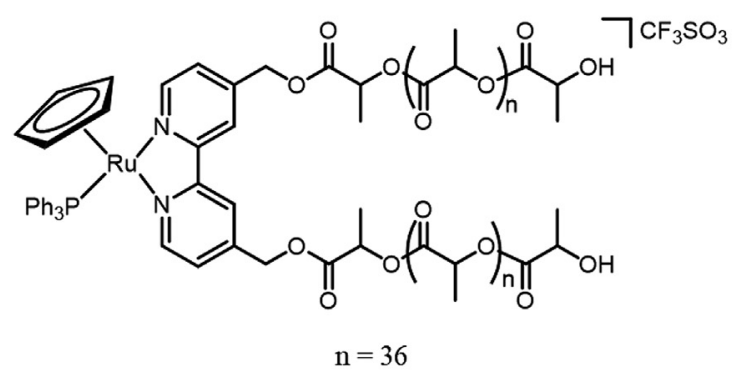

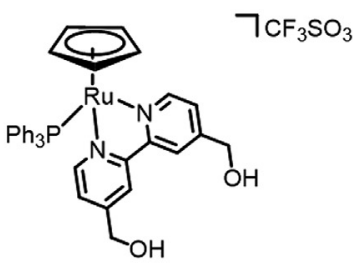

Ru1

PMC3

Fig. 2. Compounds PMC1-PMC3 and Ru1 structures.

Table 1

In vitro cytotoxic activity of complexes PMC1-PMC3 and Ru1 against A2780 ovarian, MCF7 and MDA-MB-231 breast cells at $72 \mathrm{~h}, 37^{\circ} \mathrm{C}$, measured as the half-inhibitory concentration $\left(\mathrm{IC}_{50}\right)$.

\begin{tabular}{llll}
\hline Compound & A2780 $(\mu \mathrm{M})$ & MCF7 $(\mu \mathrm{M})$ & MDA-MB-231 $(\mu \mathrm{M})$ \\
\hline Ru1 & $3.9 \pm 1.3$ & $5.9 \pm 2.3$ & $2.1 \pm 0.75$ \\
PMC1 & $1.6 \pm 0.6^{\mathrm{a}}$ & $3.9 \pm 1.4^{\mathrm{a}}$ & $3.8 \pm 0.6^{\mathrm{a}}$ \\
PMC2 & $0.21 \pm 0.03$ & $1.15 \pm 0.25$ & $1.03 \pm 0.32$ \\
PMC3 & $3.4 \pm 1.3^{\mathrm{b}}$ & $4.1 \pm 1.9^{\mathrm{b}}$ & $2.7 \pm 0.55^{\mathrm{b}}$ \\
Cisplatin & $1.9 \pm 0.1^{\mathrm{c}}$ & $36 \pm 8.0^{\mathrm{c}}$ & $110 \pm 28^{\mathrm{d}}$ \\
\hline
\end{tabular}

a Data from Ref. [40].

b Data from Ref. [41].

c Data from Ref. [67].

d Data from Ref. [47].

accordance with our previous results with related compounds [46-48]. Relatively to the polymer-metal conjugates, one might expect a different cellular uptake profile due to the higher molecular weight introduced by the polylactide chain that results in a greater accumulation inside the cells. PMC3 preferentially

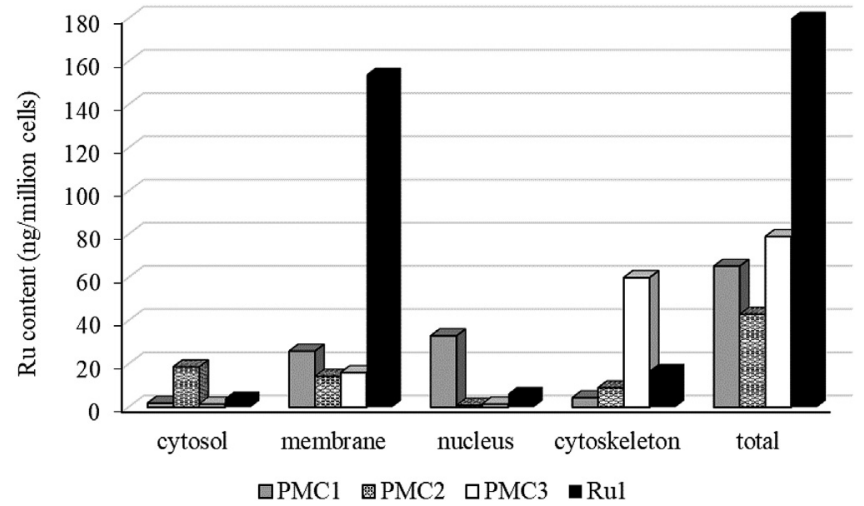

Fig. 3. Cellular Ru distribution in the MCF7 cells treated with the compounds PMC1-3 and $\mathbf{R u 1}$ at a concentration equivalent to the $\mathrm{IC}_{50}$ found at $24 \mathrm{~h}$ challenge, $37^{\circ} \mathrm{C}$. accumulates in the cytoskeleton fraction [41] and PMC2 is preferentially retained in the membrane and cytosol fractions. Comparing PMC1 [40] with PMC2, where the single difference is the size of the polylactide chain, the longer polymer chain in the case of PMC1 lead to a higher accumulation in the nuclear fraction in detriment of the cytosol uptake.

\subsection{Evaluation of the cell death mechanism induced by ruthenium- based compounds}

The cell death mechanism was assessed using Annexin V/Propidium iodide (AV/PI) cytometry-based assay. MCF7 cells were incubated with the ruthenium compounds for $48 \mathrm{~h}$ at their $\mathrm{IC}_{50}$. The results have shown that all the ruthenium-based compounds led to

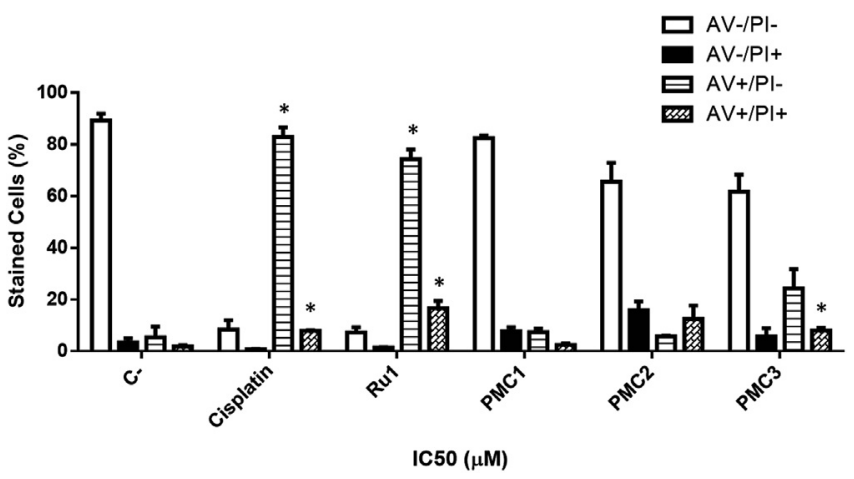

Fig. 4. Ruthenium-based compounds potentiate apoptotic cell death. MCF7 cells were incubated for $48 \mathrm{~h}$ with the ruthenium-based compounds at their $\mathrm{IC}_{50}$. Cisplatin was used as a positive control at a concentration of $25 \mu \mathrm{M}$. Graphical representation of the Annexin V/PI dotplots of cytometry data analysed using Flowing software of control, cisplatin, PMC1-PMC3 and Ru1 compounds. Values are mean \pm SD of three independent experiences. The asterisks represent the statistically significant differences in early $(\mathrm{AV}+/ \mathrm{PI}-)$ and late $(\mathrm{AV}+/ \mathrm{PI}+)$ apoptotic cells relative to the negative control. No statistically significant different was found in necrotic (AV-/PI+) cells. Statistical analysis was performed using Student's t-test. The significance was assumed for a $\mathrm{p}$ value $<0.05$. 
an increase in the percentage of $\mathrm{AV}+/ \mathrm{PI}$ - stained cells (Fig. 4) in comparison to the negative control upon treatment with cisplatin (positive control). Annexin $\mathrm{V}$ is a marker of early apoptosis, thus indicating that the type of cell death induced by this compound is apoptosis. This increase is particularly evident, and statistically significant, for the compound Ru1 (Fig. 4). Moreover, the incubation with our compounds led to a slight increase in the percentage of PI positive cells (A-/PI+) for PMC2, although not reaching statistical significance, which is indicative that this drug might also induce some necrosis as well, since PI is a marker of necrosis. The double staining with both markers $(\mathrm{A}+/ \mathrm{PI}+)$ suggests late apoptosis and the percentage of double stained cells is particularly increased with Ru1 and PMC2 compounds (Fig. 4). PMC1 did not show any significant increase in apoptosis or necrosis in comparison with the negative control. Taking into account the results obtained we can conclude that PMC3 and Ru1 induce apoptosis although only reaching statistical significance with Ru1 and the positive control cisplatin. The compound PMC2 induce apoptosis and necrosis although the increase is not statistically significant.

\subsection{Morphological analysis by transmission electron microscopy (TEM)}

Electron microscopy of the cells MCF7 treated with the compounds showed mitochondrial alterations in all treated cells (Fig. 5). These ranged from edematous and disorganized mitochondria in compounds PMC1 and Ru1, to hypertrofic mitochondria with well-developed cristae in compounds PMC2 and PMC3. Mitochondrial hypertrophy was more developed with compound PMC3. These results suggest that the ruthenium compounds may have a direct effect on mitochondria, but showing distinct patterns with different compounds. Mitochondria hypertrophy may be a compensatory response to the increased energy demand of a damaged cell, but with some of the compounds damaged mitochondria are found instead. This may indicate that these compounds may have an effect upon the mitochondria impairing energy dependent recovery mechanisms.

\subsection{Effect of PMC3 and Ru1 compounds on the cytoskeleton of cancer cells}

The cellular distribution studies suggested that PMC3 interacted with the cytoskeleton. We have thus decided to confirm these results by F-actin immunofluorescence assay using Alexa Fluor $488^{\circledR}$ phalloidin in the breast cancer cell lines MCF7 and MDA-MB-231. Phalloidin is a high-affinity filamentous actin (F-actin) probe conjugated to the green-fluorescent Alexa Fluor ${ }^{\circledR} 488$ dye. Furthermore, we included the parental Ru1 compound, due to the promising properties exhibited by this drug. Our results showed that in MCF7 control cells the integrity of the F-actin filaments are observed with a clear plasma membrane delimitation of cells. In contrast, in cells incubated with our compounds, cytoskeleton loses its organization (Fig. S1). Moreover, the appearance of some dottedlike structures inside the nuclei of cells treated with PMC3 can be observed, and might be associated with apoptotic nucleus. In the case of Ru1 treated cells, the staining with falloidin also evidenced morphological alterations indicative of a process of cell death (apoptotic bodies) that are in accordance with the results obtained with the Annexin V/PI assay.

In the case of the untreated MDA-MB-231 breast cancer derived cells one can observe a notable polarization with the cytoskeleton perfectly defining the cellular shape (observed in Fig. 6). In the same sample, several cytoskeleton extensions can be observed, cell to cell adhesions joining cells to their neighbours. In cisplatin treated samples the cells lose their polarity, presenting a more rounded shape, which is in accordance with the photomicrographs presented in Fig. 6. Moreover, cells treated with cisplatin showed depolarization of actin filaments and the cells appear to be swollen and bigger comparing with the untreated control. Additionally, the cell to cell cytoskeleton extensions are reduced in cells treated with cisplatin. PMC3 and Ru1 induce identical changes at the level of Factin organization: cells treated with these agents showed a different geometry and actin depolymerization, which is not found in untreated cells. However, and as it happens in cisplatin treated samples, it is observed a loss of cell to cell cytoskeleton extensions upon treatment with PMC3 and Ru1.
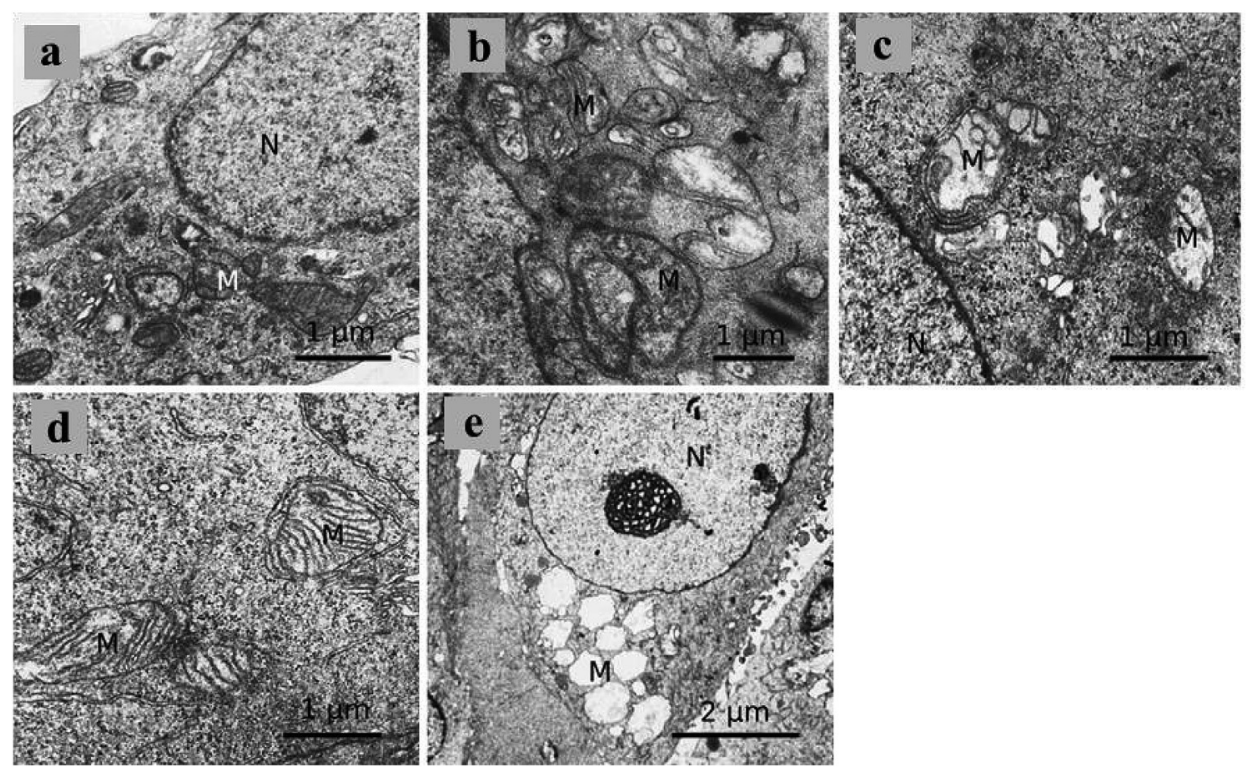

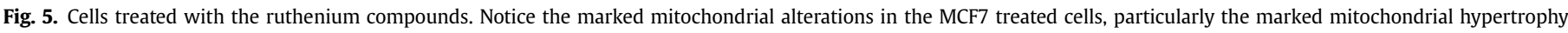
with compound PMC3, and the disorganized mitochondria with compounds PMC1 and Ru1. a) Control; b) PMC1; c) PMC2; d) PMC3; e) Ru1. 


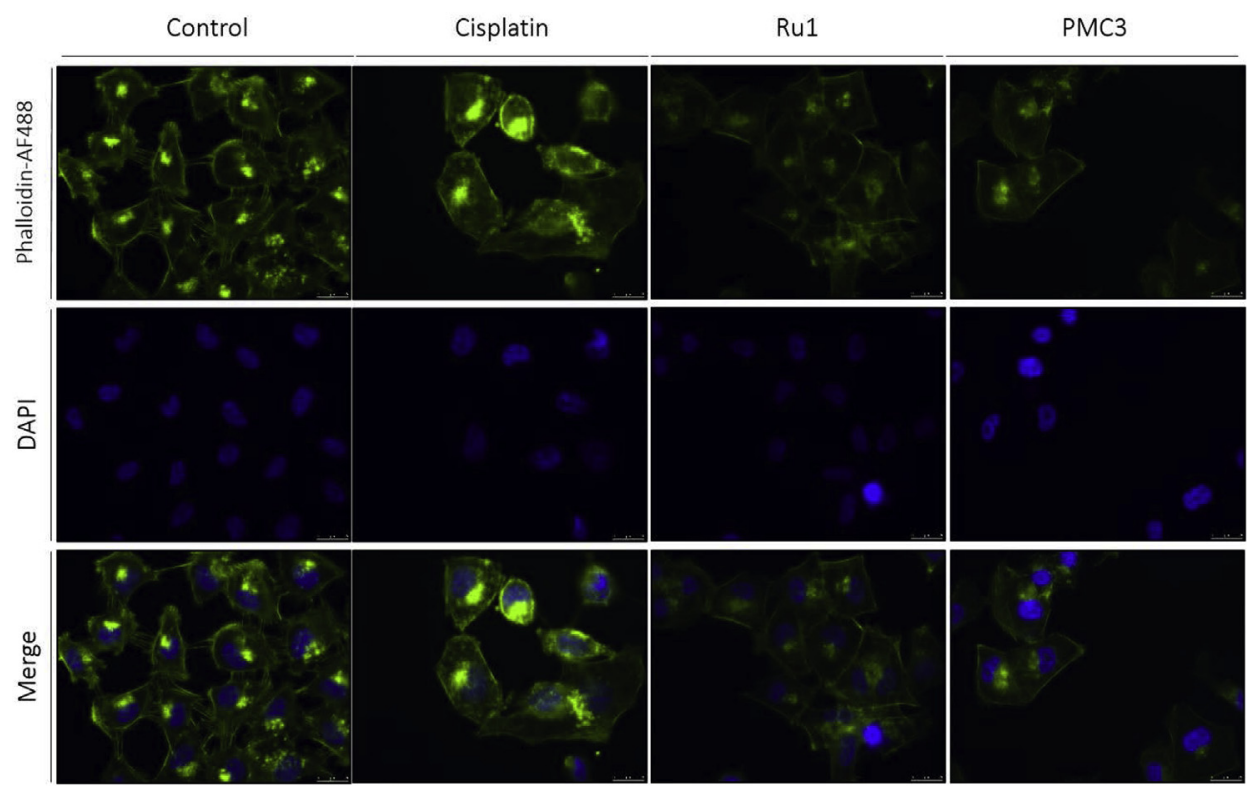

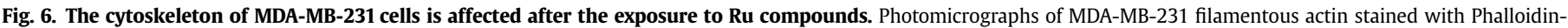

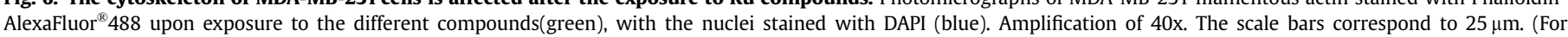
interpretation of the references to colour in this figure legend, the reader is referred to the Web version of this article.)

\subsection{The effects of PMC3 and Ru1 compounds in the clonogenic potential of cancer cells}

In order to evaluate the clonogenic potential of our rutheniumbased compounds, we evaluated their effects on survive and proliferation using MDA-MB-231 breast metastatic cancer cell line for the most promising compounds PMC3 and Ru1.

The lack of success of some chemotherapeutic regimens is based on the fact that, even after several cycles of chemotherapy, some cells may relapse and maintain their malignant potential. The colony formation assay allows us to determine the cellular ability to survive to the exposure of an exogenous agent for a short period time and to produce colonies after that agent is removed, simulating in vitro what actually happens during cycles of chemotherapy. MDA-MB-231 breast cancer derived cell line, was used as model of the Triple Negative Breast Cancer (TNBC). TNBC comprises cancers that are typically highly metastatic, with poorer prognosis and for which there is still no available effective targeted therapy [50]. Our results show that, for an exposure time of $48 \mathrm{~h}$ to the $\mathrm{IC}_{50}$ values of the respective compound, one week after the removal of the agents no cells are able to grow and form colonies (data not shown). In order to observe colonies we reduced the concentration of the compounds up to $1 / 4$ of the $\mathrm{IC}_{50}$ values. In these conditions colonies were observed and all the compounds reduced the clonogenic ability (number of colonies) of the cells (Fig. 7). The positive control cisplatin reduced dramatically the ability of these cells to form colonies, even at $1 / 4$ of its $\mathrm{IC}_{50}$. This is in accordance to the literature showing that even at lower concentrations of cisplatin, the clonogenic potential of MDA-MB-231 is extremely reduced [51]. The results presented here are very exciting regarding the possible application of these new ruthenium compounds in chemotherapy, since the number of cells that may relapse might be significantly reduced.

These results open exciting possibilities regarding the application of the compounds in chemotherapy: since chemotherapeutic regimens based on cisplatin usually raise severe side effects, our in vitro results may indicate that we may be able to obtain the same results of cisplatin using lower doses of these ruthenium-based agents.

2.7. Uptake of PMC3 and Ru1 complexes in sensitive and resistant cancer cells

One major limitation in current chemotherapy is the acquired resistance that cancer cells might develop. Cancer patients are usually treated by repeated cycles of chemotherapy and, for many, the disease relapses in the medium term. A good example to underline the importance of cisplatin treatment and resistance is the
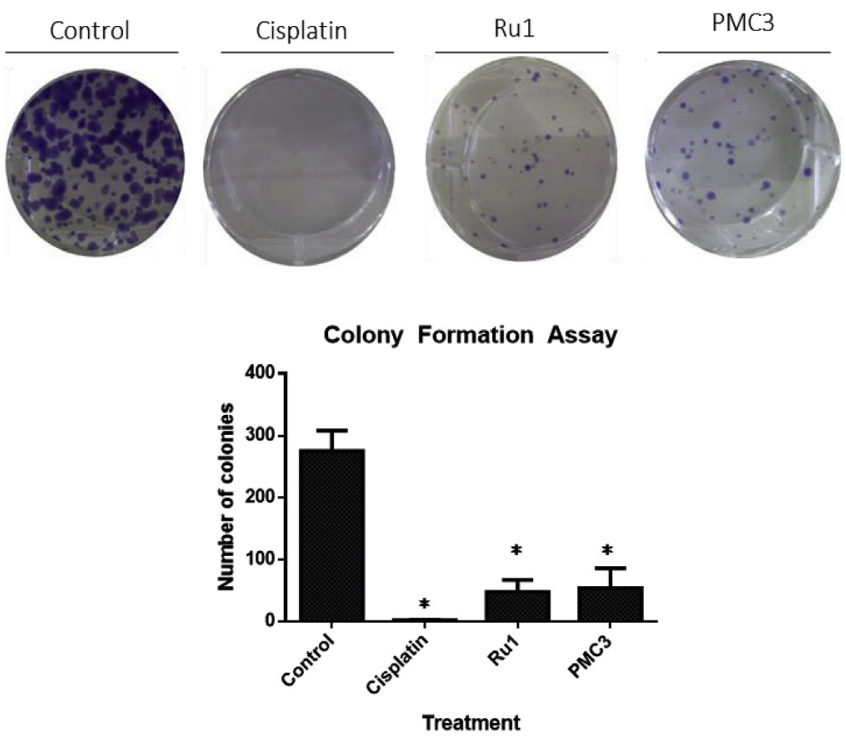

Fig. 7. Colony formation ability of MDA-MB-231 after being exposed to the ruthenium compounds. Untreated cells versus cells treated with $1 / 4$ of the $\mathrm{IC}_{50}$ of cisplatin, Ru1 and PMC3 for 48 h. Results show that all the compounds statistically reduce the clonogenic potential of this cell line. The results were obtained from at least three independent experiments, followed by Student's T-test statistical analysis. The asterisks $\left({ }^{*}\right)$ represent the statistically different results from the negative control $(p<0.05)$. 
case of ovarian cancer. Currently, the standard treatment for advanced ovarian cancer involves surgery followed by chemotherapy (first line: platinum-based drugs). Although this regimen initially results in a response rate of $40-60 \%$ in patients with advanced disease, most relapse after 18 months due to the appearance of drug-resistant tumours. Drug resistance accounts for the treatment failure and death in more than $90 \%$ of ovarian cancer in patients with advanced disease [52]. Various multidrug resistance-associated proteins (MRPs) belonging to the ABCC (ATP binding cassette subfamily $C$ ) subfamily of $A B C$ efflux transporters have been implicated to mediate resistance to platinum compounds [53]. There is now significant evidence that MRP2/ABCC2 has a major impact in the acquisition of the resistant phenotype and its reversal. Particularly in ovarian cancer, in vitro studies on A2780 and A2780cis revealed an overexpression of MRP2 in the cells [54,55] and silencing of MRP2 expression and function proved to modulate cisplatin accumulation and resistance [56-58]. Finally, the use of ABCC2 specific inhibitors allowed to reversed cisplatin resistance $[59,60]$. Thus, we wanted to verify if these new ruthenium derivatives were a MRP2 substrate. For that, flow cytometry was used to quantify their intracellular accumulation in WT vs. MRP2-expressing cells. We expect to have a high level of accumulation of the drug in the WT cells and MRP2 cells if the compound is not transported by MRP2. If the compound is a substrate of MRP2 its accumulation level will be lower than in WT. A 2-fold accumulation difference is considered expressive to proteinmediated efflux [61].

Using the LSR Fortessa and LSRII 4 lasers cytometers (BD BioSciences, San Jose, CA, USA), we opened all channels for the detection of the compounds, paying special attention to the violet channel. However, as expected from the fluorescence spectra of the compounds (they all absorb light with peaks around $260( \pm 15) \mathrm{nm}$; the fluorescence excitation spectra of the compounds show that they are all fluorescence with an emission at around $300( \pm 10) \mathrm{nm})$, we could not detect any fluorescence related to the compounds. Indeed, for both equipment, the lowest excitation wavelength is $355 \mathrm{~nm}$ (violet), therefore not suitable for the excitation of these ruthenium derivatives. For emission too, the filters make only possible the detection of light above $350 \mathrm{~nm}$. Given this technical impediment to directly screen MRP2-mediated transport, we evaluated the uptake of the compounds in sensitive and cisplatinresistant cells using mass cytometry coupled to cytometry.

In mass cytometry, the channels for the acquisition of all ruthenium isotopes (96-102 atomic weights) were opened, but during analysis we saw that the accumulation level of ruthenium was similar regardless of the chosen isotope. Therefore, the $\mathrm{Ru}^{102}$ isotope was chosen for analysis (an example of the analysis is given in Fig. S2). We also determined the uptake of platinum using the Pt 194 tag.

We started by verifying the level of accumulation of cisplatin and ruthenium in the sensitive and resistant cell lines (A2780 and A2780cis) after 20 min treatment with $20 \mu \mathrm{M}$ of the PMCs or $5 \mu \mathrm{M}$ of cisplatin. The results are given in Table 2 and represented in

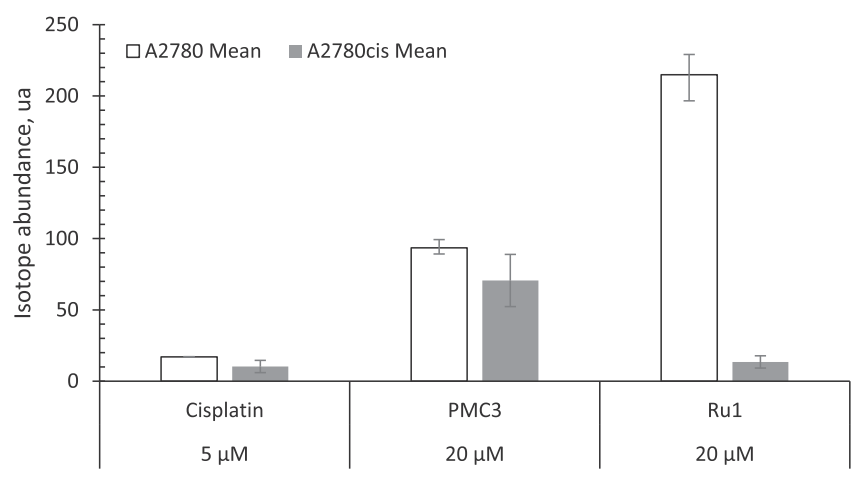

Fig. 8. Platinum and ruthenium uptake in ovarian cancer cells.

Fig. 8.

Our data shows that intracellular ruthenium accumulation varies greatly with the derivatives tested. The accumulation of the ruthenium derivatives in sensitive cells is greater than in resistant ovarian cancer cells. This result is in accordance with literature data that points out to the fact that in multidrug resistant cells many mechanisms of resistance are triggered (including impaired influx, efflux, DNA repair mechanisms, etc ...). The accumulation in the sensitive cells is an interesting aspect in the development of new drugs targeting to overcome drug resistance since an efficient accumulation in the first place could mean a better maintenance of the bioactive concentration of the drug in the cells, which might make them less susceptible to gain resistance. To avoid drug resistance due to insufficient accumulation of the drug in the cells, the aim would be to find a molecule that accumulates to the same level in both sensitive and resistant cells [62]. To see which one of our compounds is most efficient, we have calculated the differences of accumulation in sensitive and resistant cells (given in Table 3 and Fig. 9). Using the formula $\frac{\text { A2780-A2780 cis }}{\text { A2780 }} \times 100$, where A2780 represents the accumulation level in the cisplatin-sensitive cells and A2780cis that of cisplatin-resistant cells. The difference in the accumulation of the metal tag in the sensitive cells was determined and compared to resistant cells. Our goal is to find compounds with the smallest difference - the resistant cells should accumulate similar levels of the drug as the sensitive cells. As shown Table 3 and Fig. 9, the most promising candidate is the ruthenium-polymer conjugate PMC3. This compound is especially promising since the difference in the accumulation between sensitive and resistant cells

Table 3

Accumulation difference between the A2780 and A2780cis cells (\%).

\begin{tabular}{llll}
\hline Tested concentration & Compound & Accumulation difference [\%] & SD \\
\hline $5 \mu \mathrm{M}$ & Cisplatin & 40.1 & 4.5 \\
$20 \mu \mathrm{M}$ & PMC3 & 24.4 & 7.6 \\
$20 \mu \mathrm{M}$ & Ru1 & 93.7 & 1.1 \\
\hline
\end{tabular}

Table 2

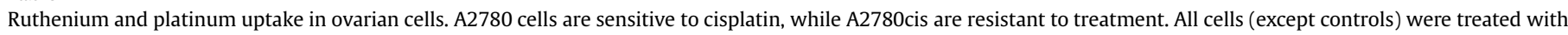
$5 \mu \mathrm{M}$ cisplatin or $20 \mu \mathrm{M}$ of each ruthenium compound.

\begin{tabular}{|c|c|c|c|c|c|c|c|}
\hline \multirow[t]{2}{*}{ Tested concentration } & \multirow[t]{2}{*}{ Compound } & \multicolumn{3}{|l|}{ A2780 } & \multicolumn{3}{|c|}{ A2780cis } \\
\hline & & Mean & SD & Corrected & Mean & SD & Corrected \\
\hline na & $\mathrm{CO}$ & 0.6 & 0.1 & 0.0 & 0.3 & 0.0 & 0.0 \\
\hline $5 \mu \mathrm{M}$ & Cisplatin & 27.1 & 5.8 & $17.1(\mathrm{CO}=10)$ & 24.6 & 4.3 & 10.3 \\
\hline $20 \mu \mathrm{M}$ & PMC3 & 94.1 & 14.2 & 93.5 & 71.0 & 18.3 & 70.6 \\
\hline $20 \mu \mathrm{M}$ & Ru1 & 215.5 & 28.9 & 214.9 & 13.9 & 4.3 & 13.5 \\
\hline
\end{tabular}

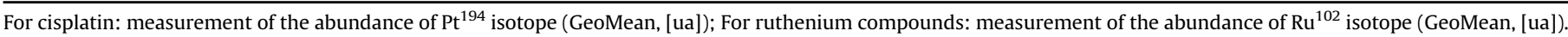




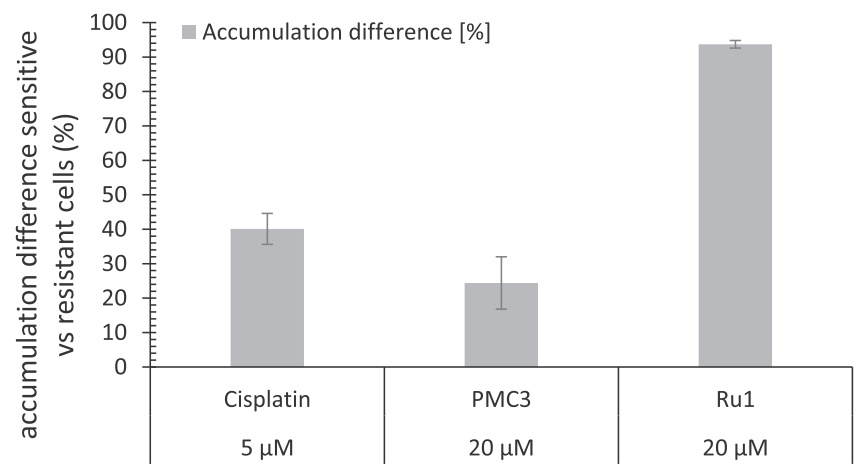

Fig. 9. Difference of accumulation of drugs (\%) between sensitive and resistant ovarian cancer cells.

is less significant than that of cisplatin (24.41\% for PMC3 compared to $40 \%$ difference in the accumulation of platinum after treatment with cisplatin). The lower accumulation level of ruthenium after 20 min treatment with PMC3 relatively to Ru1 may be explained by a slower cell uptake mechanism since after $24 \mathrm{~h}$ this is no longer the case (see data from the intracellular distribution studies). From this perspective, PMC3 might be a good candidate for a future drug since ruthenium accumulation levels after a 20-min treatment with $20 \mu \mathrm{M}$ of the drug in A2780cis cells is similar to that in A2780 cells. This means that PMC3 accumulates efficiently in both sensitive and resistant ovarian cancer cells.

\subsection{Proteomic study in MDA-MB-231 cells treated with PMC3 and Ru1}

Taking into consideration the phenotypic changes observed on the cells treated with Ru1 and PMC3, we performed a bottom-up proteomic approach using a GeLC-MS/MS strategy (protein samples included in polyacrylamide gel without fractionation were analysed by nanoLC-MS/MS after in-gel digestion) combined to two label-free quantitative methods based on Spectral Counting (SC) and Average Precursor Intensity (API) to search for the possible target-related proteins of both compounds.

A total of 354 proteins in 264 clusters were identified in MDAMB-231 cells (control and cells treated with PMC3 and Ru1) (Table S1.1-4). Functional analysis of the 354 proteins identified, corresponding to 298 unique gene names, was performed using PANTHER classification system (Fig. S3). Cellular component analysis shows that the majority of proteins are from the cellular fraction (39.8\% of cellular components hits), and $31.9 \%$ and $21.1 \%$ of proteins are from organelles and macromolecular complexes, respectively. The remaining proteins belong to different cell compartments as membrane (5\%), extracellular region (1.5\%), cell junction $(0.6 \%)$ or synapses $(0.3 \%)$. Molecular function analysis revealed that most of the proteins identified had binding activity (46.3\%) such as chaperones or nucleic acid binding proteins (33.6\%), followed by those with catalytic activity as transferases, hydrolases or oxidoreductase enzymes (28.7\%). Several proteins were also identified to have structural molecule activity (11.9\%).

From label-free quantitative proteomic experiments, out of 153 differential proteins for Ru1 or PMC3 vs control were characterized (Table S2.1). For more robustness, we retained only the 112 nonredundant proteins quantified by the two independent quantitative methods (SC and API). In total, 61 and 51 unique accession numbers were characterized differently $(\mathrm{p}<0.05$, fold change $>2)$ between Ru1 or PMC3 treated cells with the control cells, respectively (Table S2.2 and S2.3). Comparison between control cells and those treated with $\mathbf{R u 1}$ shows that 21 proteins are more abundant in Ru1 treated condition and 40 proteins are less abundant. For cells treated with PMC3, 34 proteins are more abundant in PMC3 treated condition and 17 proteins are less abundant.

For cells treated with PMC3, the molecular functions analysis using PANTHER revealed that majority of the less abundant proteins were involved in binding (55.60\%), and especially in nucleic acid binding as transcription factors, while proteins with higher abundance belong to the catalytic activity (55.60\%) and binding (25.90\%) protein classes. For cells treated with Ru1, as observed for PMC3, a high percentage of the less abundant proteins in Ru1 treated cells were linked to binding protein class (53.70\%), in which $41 \%$ are nucleic acid binding proteins, and the majority of the more abundant proteins were involved in catalytic activity (50\%) and binding (27.80\%).

Based on STRING protein-protein interaction predictions, an association network of the proteins, which have their expression modified due to the treatment with PMC3 or Ru1, was created (Figs. S4 and S5). We were especially interested on those proteins related to the observed phenotypic alterations, such as those involved in the cytoskeleton dynamics, mitochondrial and involved in apoptosis. This bioinformatics analysis indicated that an important group of proteins identified in PMC3 were related to cellular cytoskeleton dynamics, cell stress, namely endothelial reticulum stress, cell cycle and apoptosis. A closer analysis leads us to postulate that proteins that regulate the microtubule dynamics are the target of PMC3 which might be associated to the fact that this compound inhibit proliferation that might be due to an arrest of mitosis. Indeed, microtubules dynamic are pivotal for mitosis occurrence as they are the crucial constituents of the mitotic spindle essential for chromosomes separation during mitosis [63].

Moreover, at the beginning of mitosis (prophase, prometaphase), several cellular components are disassembled, including the nuclear envelope, the nuclear lamina and the nuclear pore complexes. The nuclear breakdown is necessary to allow the mitotic spindle to interact with the kinetochores of the condensed chromosomes [63]. Here we also gathered results supporting again the role of PMC3 in cell cycle arrest, as we found an upregulation of Prelamin-A/C (LMNA), a mitosis-promoting factor, that causes depolymerization of the lamin intermediate filaments, and the downregulation of lamina-associated polypeptide 2 (TMPO) protein involved in the transport to the plus end of the microtubules, assembly of the nuclear lamina and maintenance of individual mitotic chromosomes dispersed in the cytoplasm following nuclear envelope disassembly [63]. Moreover, there is also experimental evidence of chromatin condensation at the cells treated with PMC3 (Fig. S1 and Fig. 5). These evidences might be related also to the apoptosis process, where there is nucleic acid degradation and in which the nuclear lamina is disassembled in an early stage. This sequence of events induces endoplasmic reticulum stress leading to an increase of the heat shock proteins and chaperones as a response for the cell stress [64]. We can hypothesise that since the cytoskeleton has lost its organization (as also observed on our experimental data), the proteins might no longer be capable to move along from the ER to their destiny.

The results from this bioinformatics analysis indicated the groups of proteins deregulated after treatment with Ru1 are the same as PMC3, i.e., cellular cytoskeleton dynamics, cell stress, cell cycle and apoptosis. However, in the case of Ru1, there are several proteins related to cell adhesion and migration that are downregulated, what is in accordance with the phenotypic alterations observed, namely changes in the actin organization and loss of cell to cell cytoskeleton extensions. A closer analysis on the proteins lead us to postulate that proteins that regulate the actin dynamics are the target of Ru1 which might explain why Ru1 induce cell cycle arrest at G2/M phase. Actin cytoskeletal organization is important 
for cell cycle progression. Cofilin-1, one of the down-regulated proteins, is a member of the actin depolymerizing factor (ADF)/ cofilin family that is required for the regulation of actin dynamics. Cofilin regulates the dynamics of the actomyosin-based contractile ring being essential for cell division during mitosis [63]. Interestingly, loss of cofilin expression leads to G2/M phase arrest and to the formation of multinucleate cells, what is in accordance with our observations in Fig. 6.

Overall, the proteomic study correlated well with the phenotypic alterations observed such as mitochondrial hypertrophy, disorganization of cytoskeleton, cell cycle arrest and apoptosis.

\section{Conclusion}

Taking into consideration all the results obtained from the different biological studies that have been performed, the polymerruthenium conjugate PMC3 is doubtless the most promising metallodrug that might constitute a lead molecule to pursuit in the future. This compound has shown good cytotoxic activity towards three cancer cell lines harbouring different genetic alterations. All compounds induce inhibition of proliferation and apoptosis, interfering with mitochondria and with cytoskeleton in the MCF7 cancer cell line. PMC3 also highly reduces the colony formation potential of MDA-MB-231 breast cancer cells. A closer analysis by a bottom-up proteomic approach of the proteins involved in the phenotypic changes observed, lead us to postulate that those proteins responsible for the regulation of the microtubule dynamics are the target of PMC3. Such a mechanism seams similar to that observed for the drug Paclitaxel that suppresses microtubule dynamics, causing the block of mitotic activity leading to apoptosis [65]. These results place PMC3 within a new class of drugs called migrastatic agents [66], i.e. anti-metastatic and anti-invasion drugs which targets are actin polymerization and contractility.

Importantly, PMC3 might not be subject of protein-mediated efflux from A2780cis ovarian human cancer cells, contrarily to Ru1. This result is of upmost importance since resistance to treatment is a major threat for the success of chemotherapy.

Summing up, we have disclosed important hints on the mechanism of action of new ruthenium(II) compounds which might be of potential interest for the therapy of metastatic and resistant cancers. PMC3 seem to be a lead molecule to pursuit in the future, and the potential of this compound might even be improved by its functionalization with biomolecules of interest in order to induce a receptor-mediated internalization towards a dual passive and active targeting.

\section{Experimental section}

\subsection{Compounds under study}

All syntheses were carried out under dinitrogen atmosphere using current Schlenk techniques and the solvents used were dried using standard methods. All compounds were synthesized using protocols recently reported by us (PMC1-2 [40], PMC3 [41], Ru1 [42]).

\subsection{Biological activity evaluation}

\subsubsection{Cell lines}

The MDCKII (Madin-Darby Canine Kidney II) WT and MRP2 cell lines were kindly offered by Pr. Piet Borst, (The Netherlands Cancer Institute, Amsterdam, Netherlands). They are epithelial kidney cells, and the MDCKII-MRP2 cell line was generated by transfection with a pCMV-cMOAT retrovirus (clone 17; MDCKII-MOAT17) [70]. The A2780 and A2780cis are ovarian cancer cell lines, purchased from Sigma Aldrich (for flow cytometry studies) or to ATCC (cytotoxicity evaluation). Cisplatin resistant cell line A2780cis (Sigma no. 93112517) is derived from A2780 cell line and it has been developed by chronic exposure of the parent cisplatin-sensitive A2780 cell line (Sigma no. 93112519) to increasing concentrations of cisplatin. A2780cis is cross-resistant to other drugs such as melphalan and adriamycin. An increased ability to repair DNA damage as well as cytogenetic abnormalities has been observed. The MCF7 and MDAMB-231 breast cancer human tumour cell lines were purchased to ATCC.

\subsubsection{Cell culture}

MDCKII cells were cultured in Dulbecco's modified Eagles' medium (DMEM high glucose) supplemented with $10 \%$ fetal bovine serum (FBS), 1\% penicillin/streptomycin, without selection for the MRP2-transfected cell line. A2780 and A2780cis cell lines were cultured in RPMI medium with $10 \%$ FBS and $1 \%$ penicillin/streptomycin. Cisplatin was added every $2-3$ passages to the media to the resistant cell line, in order to retain its resistance. MCF7 and MDAMB-231 breast cancer human tumour cell lines were grown in cell culture flasks in a $5 \% \mathrm{CO}_{2}$ incubator at $37{ }^{\circ} \mathrm{C}$ with humidified atmosphere (Heraeus, Germany). The culture media DMEM with Glutamax I was supplemented with $10 \%$ FBS (fetal bovine serum) and $1 \%$ penicillin/streptomycin. All the cells were adherent in monolayers and, upon confluence, were harvested by digestion with trypsin-EDTA (Gibco).

\subsubsection{Cell viability assays in human tumour cell lines}

The cytotoxic activity of the Ru complexes against the tumour cells was assessed using the MTT assay based on the reduction of the tetrazolium dye to formazan. For this purpose, cells were seeded into 96 -well plates at a density of approx. $10 \times 10^{3} / 200 \mu \mathrm{L}$ medium and incubated for $24 \mathrm{~h}\left(37^{\circ} \mathrm{C} / 5 \% \mathrm{CO}_{2}\right)$ to adhere. Compounds were dissolved in DMSO and then in medium and added to the cells in serial dilutions in the range $10 \mathrm{nM}-100 \mu \mathrm{M}$. At the end of incubation time, the treatment solution was discarded and a MTT solution $(0.5 \mathrm{mg} / 200 \mathrm{~mL}$ PBS $)$ was added to each well. After $3 \mathrm{~h}$ at $37^{\circ} \mathrm{C} / 5 \% \mathrm{CO}_{2}$, the solution was removed and the formazan crystals formed inside the cells were dissolved in $200 \mu \mathrm{L}$ DMSO. The absorbance values were measured at $570 \mathrm{~nm}$ using an ELISA reader (PowerWave Xs, Bio-Tek Instruments, Winooski, VT, USA). The IC50 values were determined by nonlinear regression using GraphPad Prism software version 4.0.

\subsubsection{Cellular uptake by ICP-MS analysis}

For the cellular uptake experiments, MCF7 cells ( $c a .10^{6}$ cells/ $5 \mathrm{~mL}$ medium) were exposed to the complexes at a concentration equivalent to their $\mathrm{IC}_{50}$ values found for $24 \mathrm{~h}$ challenge, $37^{\circ} \mathrm{C}$. After incubation cells were then washed with ice-cold PBS and treated in order to obtain a cellular pellet [67]. The cytosol, membrane/particulate, cytoskeletal and nuclear fractions were extracted using a FractionPREPTM, cell fractionation kit (BioVision, USA) and performed according to the manufacturer's protocol. The $\mathrm{Ru}\left({ }^{101} \mathrm{Ru}\right)$ content in each fraction was measured by a Thermo X-Series Quadrupole ICP-MS (Thermo Scientific) after digestion of the samples and using the same procedure previously described [67].

\subsubsection{Cell death measurement by flow cytometry, Annexin V/PI assay}

AV/PI assay is widely used to determine cellular apoptosis as it allows to differentiate between apoptotic, or necrotic cells through differences in plasma membrane integrity and permeability [49]. After $48 \mathrm{~h}$ of treatment with the compounds both suspended and attached cells were collected and washed in $1 \mathrm{x}$ PBS. $1 \times 10^{6}$ cells were resuspended in $100 \mu \mathrm{L} 1 \mathrm{x}$ binding buffer and incubated with 
$5 \mu \mathrm{L}$ AV- fluorescein isothiocyanate (BD Biosciences, San Jose, CA, USA) and $10 \mu \mathrm{L} 50 \mu \mathrm{g} / \mathrm{mL}$ PI for $15 \mathrm{~min}$ in the dark. Samples were analysed in an Epics ${ }^{\mathbb{R}}$ XLTM (Beckman Coulter) cytometer, equipped with an argon-ion laser emitting a $488-\mathrm{nm}$ beam at $15 \mathrm{~mW}$. Monoparametric detection of red fluorescence was performed using FL-4 (488/675 nm) and detection of green fluorescence was performed using FL-1 (488/525 nm). 20000 cells were analysed per sample and data analysed using Flowjo software (version 7.6, Tree Star Inc., Ashland, OR, USA).

\subsubsection{Morphological analysis by transmission electron microscopy TEM}

MCF7 cells at approximately 70\% confluence were treated with all the complexes at a concentration equivalent to their $\mathrm{IC}_{50}$ values at $24 \mathrm{~h}$ challenge, $37^{\circ} \mathrm{C}$. Untreated cells were used as controls. After incubation, the culture medium was discarded and replaced by $5 \mathrm{~mL}$ of primary fixative consisting of $3 \%$ glutaraldehyde in $0.1 \mathrm{M}$ sodium cacodylate buffer $\mathrm{pH}$ 7.3. Following primary fixation for $2 \mathrm{~h}$ at $4{ }^{\circ} \mathrm{C}$ and wash in the cacodylate buffer $(5 \mathrm{~mL})$, cells were scrapped, pelleted and embedded in $2 \%$ agar for further processing. Samples were further fixed for $3 \mathrm{~h}$ in $1 \%$ osmium tetroxide in $0.1 \mathrm{M}$ sodium cacodylate buffer $\mathrm{pH}$ 7.3. Then, samples were washed in $0.1 \mathrm{M}$ acetate buffer, $\mathrm{pH} 5.0$ and fixed in $0.5 \%$ uranyl acetate in the same buffer for $1 \mathrm{~h}$. Dehydration was carried out with increasing concentrations of ethanol. After passing through propylene oxide, samples were embedded in Epon-Araldite, using SPI-Pon as an Epon 812 substitute. Thin sections were made with glass or diamond knives and stained with $2 \%$ aqueous uranyl acetate and Reynold's lead citrate. The stained sections were analysed and photographed in a JEOL 1200-EX electron microscope.

\subsubsection{Effect of compounds PMC3 and Ru1 on cytoskeleton, F-actin staining}

For visualization of actin fibres, cells were seeded in cover-slips allowing the cell attachment overnight. Cells where then treated with the $\mathrm{IC}_{50}$ of the compounds for $48 \mathrm{~h}$. After the incubation time the cells where washed with warm PBS and fixed for $20 \mathrm{~min}$ in $2.5 \%$ of Glutaraldehyde. Furthermore, cells where washed with PBS and permeabilized with $0.1 \%$ of Triton X-100 for $5 \mathrm{~min}$. After another washing step cells were incubated in the dark with Alexa Fluor ${ }^{\circledR}$ 488 phalloidin for $20 \mathrm{~min}$. For fluorescence microscope visualization in inverted microscope (Olympus IX71), the excess of fluorophore was washed with PBS and coverslips where mounted with vectashield mounting medium.

\subsubsection{Colony formation assay}

MDA-MB-231 were seeded in 6-well plates at 400 cells $/ \mathrm{mL} .24 \mathrm{~h}$ after plating, cells were incubated with $1 / 4$ of the $\mathrm{IC}_{50}$ value of the different compounds. $48 \mathrm{~h}$ after the incubation, old medium was removed and cells were incubated with fresh medium. Medium was renewed every 3 days. 7 days after removing the treatments, cells were washed with PBS and incubated in a solution of glutaraldehyde $(6 \%(\mathrm{v} / \mathrm{v}))$ with crystal violet $(0.5 \%(\mathrm{w} / \mathrm{v}))$ for at least half an hour. The plate was washed with fresh water and left air dry. Colonies were counted manually. The negative control was incubated with the correspondent volume of DMSO used in the solubilisation of the compounds (vehicle), and the final concentration of DMSO per well did not exceed $0.1 \%$.

\subsubsection{Fluorescence tests and flow-cytometry}

4.2.9.1. Fluorescence spectra. To determine the fluorescence emission spectra of the compounds, they were prepared at $10 \mu \mathrm{M}$ in a mixture of DMSO and distilled water (1:10). Using a TECAN 50000 equipment, we first determined the absorption spectra, then the fluorescence excitation wavelength and the fluorescence emission spectra.

4.2.9.2. Flow cytometry. MDCKII WT and MRP2 cells were seeded at a density of $10^{5}$ cells/well into 24 -well culture plates. After a 48 -h incubation period, they were exposed to different concentrations of compounds for $30 \mathrm{~min}$ at $37^{\circ} \mathrm{C}$, and then they were incubated for $30 \mathrm{~min}$ at $37^{\circ} \mathrm{C}$ in the presence of $10 \mu \mathrm{M}$ of each compound as substrate. After treatment, the cells were then washed with phosphate buffer saline and trypsinized. The intracellular fluorescence was monitored with LSR Fortessa and LSRII 4 lasers cytometers (BD Biosciences, San Jose, CA, USA), using the fluorescence channels, and at least 5000 events were collected.

4.2.9.3. Evaluation of the uptake of the compounds in single cells by mass cytometry. In this technique, cells are stained with a stable isotope tag and injected into a mass spectrometer coupled with a cytometer. Cells are vaporized, atomized and ionized in a (high temperature) Inductively Coupled Plasma (ICP), and the atomic composition of each cell (including metal tags) is measured by time of flight mass spectrometry (TOF-MS), generating distinct mass spectra of each cell. The mass cytometer is also capable of measuring heavy elements naturally present or introduced into a cell, such as iodine and platinum [68]. Reporter ions are quantified by time of flight mass spectrometry. Data is parsed into single cell events and converted to a flow cytometry standard (FCS) file for analysis [69]. We evaluated the transport of ruthenium derivatives in MDCKII WT and MRP2 cells and in ovarian cancer cells sensitive and resistant to cisplatin A2780 and A2780cis. Cells were seeded in 6 -wells plates for $48 \mathrm{~h}$ to reach a density of $\sim 1$ million cells $/ \mathrm{mL}$. Cells were treated for $15 \mathrm{~min}$ with $20 \mu \mathrm{M}$ of each compound. We used $5 \mu \mathrm{M}$ of cisplatin to verify the different accumulation levels in each cell line. After treatment, cells were washed with PBS and then fixed in $1 \mathrm{~mL}$ PFA 4\%. Next day, the supernatant was discarded and we marked DNA of the cells with iridium. Then we carefully washed the cells for remaining traces of metals with MaxPar Water. Cells were analysed using a cyTOF mass cytometer (DVS Sciences Inc, Markham, ON, Canada). A minimum of $5 \times 10^{4}$ events were collected for each sample. Channels for all ruthenium isotopes were opened (atomic masses 96, 98-102, 104), as well as the channels for iridium (atomic masses 191 and 193) and platinum (atomic masses 190, 192, 194-196, 198). Data in FCS format was analysed using the FlowJo v10.0.7 software - GeoMean $\mathrm{Ir}^{191}, \mathrm{Ir}^{193}, \mathrm{Pt}^{194}, \mathrm{Ru}^{102}$.

\subsection{Data analysis}

All tests were done in duplicates and statistical analysis was conducted using specialized software. Flow-cytometry analysis was done using the FlowJo V.10.0.7 software. Statistical analysis was done using Excel.

\subsection{Proteomic study}

\subsubsection{Collection and preparation of cells}

MDA-MB-231 cells were cultivated as described previously. For each condition (PMC3, Ru1, control), we performed two biological replicates (pool 1 and 2). The cells were non-enzymatically harvested using a $0.48 \mathrm{mM}$ PBS-EDTA solution $\left(4^{\circ} \mathrm{C}\right)$. Upon detachment, the cells were collected and centrifuged at $800 \times \mathrm{g}$ for $8 \mathrm{~min}$. The pellets were washed with PBS and centrifuged again. This washing step was repeated three times. The pellets were kept at $-80^{\circ} \mathrm{C}$ until needed for further studies.

\subsubsection{Sample preparation for MS analysis}

The cells were sonicated in a lysis buffer containing $50 \mathrm{mM}$ Tris$\mathrm{HCl}, \mathrm{pH} 7.5,150 \mathrm{mM} \mathrm{NaCl}, 1 \% \mathrm{NP}-40,1 / 10$ phosphatase inhibitor 
cocktail (PhosSTOP, Roche) and $1 / 20$ protease inhibitor cocktail (P2714, Sigma) and centrifuged $10 \mathrm{~min}, 4^{\circ} \mathrm{C}$ at $10,000 \times \mathrm{g}$. The supernatant protein concentrations were determined using a $\mathrm{BC}$ Protein Assay (Interchim, Montlucon Cedex, France), using bovine serum albumin (Sigma-Aldrich, Saint Quentin Fallavier, France) as the standard. SDS-PAGE (minigel $8.3 \times 6 \mathrm{~cm} \times 1 \mathrm{~mm}$ ) was carried out to include the proteins within a $10 \%$ polyacrylamide gel, without fractionation $(50 \mathrm{~V}, 20 \mathrm{~min})$, with a protein load of $37 \mu \mathrm{g}$ total protein per lane. The gel was then stained with Coomassie blue (overnight at room temperature (RT) with agitation). The whole lane (one band) was excised for tryptic digestion and mass spectrometry (MS) analysis.

Gel pieces were washed in a solution of water:acetonitrile $(1: 1$, $5 \mathrm{~min}$ ) followed by $100 \%$ acetonitrile $(10 \mathrm{~min})$. Reduction and cysteine alkylation were performed by successive incubations with $10 \mathrm{mM}$ dithiothreitol in $50 \mathrm{mM} \mathrm{NH} \mathrm{NCO}_{3}\left(30 \mathrm{~min}, 56^{\circ} \mathrm{C}\right)$, then $55 \mathrm{mM}$ iodoacetamide in $50 \mathrm{mM} \mathrm{NH} \mathrm{HCO}_{3}$ (20 min, RT, in dark). Pieces were then incubated with $50 \mathrm{mM} \mathrm{NH}_{4} \mathrm{HCO}_{3}$ and acetonitrile $(1: 1,10 \mathrm{~min})$ followed by acetonitrile ( $15 \mathrm{~min})$. Proteolytic digestion was carried out overnight using $25 \mathrm{mM} \mathrm{NH}_{4} \mathrm{HCO}_{3}$ with $12.5 \mathrm{ng} / \mu \mathrm{l}$ Trypsin (Sequencing grade, Roche diagnostics, Paris, France). Resultant peptides were extracted by incubation in $5 \%$ formic acid (sonicated) with the supernatant removed and saved, followed by incubation in acetonitrile and $1 \%$ formic acid (1:1, $10 \mathrm{~min})$ and a final incubation with acetonitrile ( $5 \mathrm{~min}$ ), again supernatant was removed and saved. These two peptide extractions were pooled and dried using a SPD1010 SpeedVac system (Thermosavant, Thermofisher Scientific, Bremen, Germany) and the peptide mixture was analysed by MS.

\subsubsection{NanoLC-MS/MS analysis}

After in-gel digestion by trypsin, peptide mixtures were analysed by on-line nanoflow liquid chromatography tandem high resolution mass spectrometry (nanoLC-MS/MS). For each biological sample (pool 1 and 2) and for each condition (PMC3, Ru1 and control), we performed four technical replicates. All experiments were performed on a dual linear ion trap Fourier Transform Mass Spectrometer LTQ Orbitrap Velos (Thermo Fisher Scientific, Bremen, Germany) coupled to an Ultimate ${ }^{\circledR} 3000$ RSLC Ultra High Pressure Liquid Chromatographer (Thermo Fisher Scientific, Bremen, Germany) controlled by Chromeleon Software (version 6.8 SR11). Samples were desalted and concentrated for 10 min at $5 \mu \mathrm{L} /$ min on an LCPackings trap column (Acclaim PepMap 100C18, $75 \mu \mathrm{m}$ inner diameter $\mathrm{x} 2 \mathrm{~cm}$ long, $3 \mu \mathrm{m}$ particles, $100 \AA$ pores). The peptide separations were conducted using a LCPackings nano-column (Acclaim PepMap C18, $75 \mu \mathrm{m}$ inner diameter x $50 \mathrm{~cm}$ long, $2 \mu \mathrm{m}$ particles, $100 \AA$ A pores) at $300 \mathrm{~nL} / \mathrm{min}$ by applying gradient consisted of $4-60 \%$ B during $180 \mathrm{~min}$. Mobile phases consisted of (A) $0.1 \%$ formic acid, $97.9 \%$ water, $2 \%$ acetonitrile $(\mathrm{v} / \mathrm{v} / \mathrm{v})$ and (B) $0.1 \%$ formic acid, $15.9 \%$ water, $84 \%$ acetonitrile ( $\mathrm{v} / \mathrm{v} / \mathrm{v})$.

Data were acquired in positive ion mode and in data-dependent mode to automatically switch between high resolution full-scan MS spectra ( $\mathrm{R} 60000$ ) in the $300-1800 \mathrm{~m} / \mathrm{z}$ mass range and MS/MS spectra. The 20 most intense peptide ions with charge states $\geq 2$ were sequentially isolated and fragmented in the high pressure linear ion trap using CID mode (collision energy 35\%, activation time $10 \mathrm{~ms}$, Qz 0.25). Dynamic exclusion was activated during $30 \mathrm{~s}$ with a repeat count of 1 . The lock mass was enabled for accurate mass measurements. Polydimethylcyclosiloxane $(\mathrm{m} / \mathrm{z}$, 445.1200025, $\left.\left(\mathrm{Si}\left(\mathrm{CH}_{3}\right)_{2} \mathrm{O}\right)_{6}\right)$ ion was used for internal recalibration of the mass spectra.

\subsubsection{Protein identification and validation}

MS/MS ion searches were performed using Mascot search engine version 2.3.02 (Matrix Science, London, UK) via Proteome
Discoverer 2.1 software (ThermoFisher Scientific, Bremen, Germany) against SWISSPROT_mammalian databases (144 541 entries, download 01/01/2017). The search parameters included trypsin as a protease with two allowed missed cleavages and carbamidomethylcysteine, methionine oxidation and acetylation of N-term protein as variable modifications. The tolerance of the ions was set to $5 \mathrm{ppm}$ for parent and 0.8 Da for-fragment ion matches. Mascot results obtained from the target and decoy databases searches were subjected to Scaffold software (v 4.8.4, Proteome Software, Portland, USA) using the protein cluster analysis option (assemble proteins into clusters based on shared peptide evidence). Peptide and proteins identifications were accepted if they could be established at greater than $95.0 \%$ probability as specified by the Peptide Prophet algorithm and by the Protein Prophet algorithm, respectively [71,72]. Protein identifications were accepted if they contained at least two identified peptide. The False Discovery Rate (FDR) was $<0.01 \%$.

\subsubsection{Label-free protein quantifications}

For comparative analyses, we employed Scaffold $\mathrm{Q}+$ software (version 4.8.4, Proteome Software, Portland, USA) to apply two independent quantitative methods: 1 ) the Spectral Counting which counts and compares the number of fragment spectra identifying peptides of a given protein; 2) the Average Precursor Intensity which measures and compares the mass spectrometric signal intensity of peptide precursor ions belonging to a particular protein. Quantification was performed using the "Weighed Spectra" method where the weight is a measure of how much a spectrum is shared by other proteins. Thus, numbers of Normalized Weighed Spectra (NWS) were tabulated using experiment wide protein clustering. The reproducibility linked directly to the nanoLC-MS methodology was evaluated by the coefficient of variance (CV) for each condition (pool1-2 for PMC3 or Ru1 vs control) considering 4 technical replicates and for each protein group (Table S2.4). Significance between treatments and control was determined using statistical tests within Scaffold software; t-tests for SC and API quantification, where $\mathrm{p}<0.05$ was considered significant. Limits of an average normalized weighted spectra (NWS) of $\geq 5$ and fold change/ratio of $\geq 2$ were included to increase validity of any comparisons made.

\subsubsection{Gene ontology, localisation and network analysis}

Gene symbols (human orthologs) were mapped for all protein identifications and analysed using two different bioinformatics tools. In order to estimate which cell compartments/functions are mainly represented by the identified proteins, a systems biology analysis was performed using PANTHER [73] (Protein ANalysis THrough Evolutionary Relationships) Classification System (v 13.1 released 2018-02-03, www.pantherdb.org). Homo sapiens organism was selected to maximise classifications. Predicted protein-protein associations were evaluated using STRING [74] database (v 10.5, www.string-db.org) on lists of differential proteins characterized for PMC3 or Ru1 conditions with control. Networks were extracted for proteins presenting more or less abundant in PMC3 or Ru1 conditions.

\section{Acknowledgements}

This work was financed by the Portuguese Foundation for Science and Technology (Fundação para a Ciência e a Tecnologia, FCT) within the scope of projects UID/QUI/00100/2013 and PTDC/QUIQIN/28662/2017. This work was supported by the strategic program UID/BIA/04050/2013 (POCI-01-0145-FEDER-007569) funded by national funds through the FCT I.P. and by the ERDF through the COMPETE2020 - Programa Operacional Competitividade e Internacionalização (POCI). Andreia Valente acknowledges the COST 
action CM1302 (SIPs), the Investigator FCT2013 Initiative for the project IF/01302/2013 (acknowledging FCT, as well as POPH and FSE - European Social Fund) and the Royal Society of Chemistry's Research Fund. Pierre Falson and Elisabeta Comsa warmly acknowledge Thibault Andrieu from the cytometry plateau of SFR bioscience -UMS 3444- at Lyon-Gerland, France for assistance on CytoF. This work was also supported by the Marie Curie Initial Training Network: FP7-PEOPLE-2012-ITN proposal $n^{\circ} 317297$ acronym GLYCOPHARM and PITN-GA-2012-317297. The highresolution mass spectrometer at CIRE-PAIB was financed (SMHART project $n^{\circ} 3069$ ) by the European Regional Development Fund (ERDF), the Conseil Régional du Centre, the French National Institute for Agricultural Research (INRA) and the French National Institute of Health and Medical Research (Inserm).

\section{Appendix A. Supplementary data}

Supplementary data to this article can be found online at https://doi.org/10.1016/j.ejmech.2019.02.061.

\section{References}

[1] S.J. Shirbin, K. Ladewig, Q. Fu, M. Klimak, X. Zhang, W. Duan, G.G. Qiao, Cisplatin-induced formation of biocompatible and biodegradable polypeptidebased vesicles for targeted anticancer drug delivery, Biomacromolecules 16 (2015) 2463-2474.

[2] S. Aroui, L. Dardevet, W.B. Ajmia, M. de Boisvilliers, F. Perrin, A. Laajimi A. Boumendjel, A. Kenani, J.M. Muller, M. De Waard, A nove Platinum-Maurocalcine conjugate induces apoptosis of human glioblastoma cells by acting through the ROS-ERK/AKT-p53 pathway, Mol. Pharm. 12 (2015) 4336-4348

[3] Y. Yuan, R.T.K. Kwok, B.Z. Tang, B. Liu, Targeted theranostic platinum(IV) prodrug with a built-in aggregation-induced emission light-up apoptosis sensor for noninvasive early evaluation of its therapeutic responses in situ, J. Am. Chem. Soc. 136 (2014) 2546-2554

[4] A. Gandioso, E. Shaili, A. Massaguer, G. Artigas, A. González-Cantó, J.A. Woods, P.J. Sadler, V. Marchán, V, An integrin-targeted photoactivatable Pt(IV) complex as a selective anticancer pro-drug: synthesis and photoactivation studies, Chem. Commun. 51 (2015) 9169-9172.

[5] N. Graf, T.E. Mokhtari, I.A. Papayannopoulos, S.J. Lippard, Platinum(IV)-chlorotoxin (CTX) conjugates for targeting cancer cells, J. Inorg. Biochem. 110 (2012) 58-63.

[6] L. Gaviglio, A. Gross, N. Metzler-Nolte, M. Ravera, Synthesis and in vitro cytotoxicity of cis,cis,trans-diamminedichloridodisuccinatoplatinum(IV)peptide bioconjugates, Metallomics 4 (2012) 260-266.

[7] N. Margiotta, N. Denora, R. Ostuni, V. Laquintana, A. Anderson, S.W. Johnson, G. Trapani, G. Natile, Platinum(II) complexes with bioactive carrier ligands having high affinity for the translocator protein, J. Med. Chem. 53 (2010) $5144-5154$

[8] J. Ji, P. Zuo, Y.-L. Wang, Enhanced antiproliferative effect of carboplatin in cervical cancer cells utilizing folate-grafted polymeric nanoparticles, Nanoscale Res. Lett. 10 (2015) 453, 8 pages.

[9] P. Liu, L. Sun, D.-S. Zhou, P. Zhang, Y.-H. Wang, D. Li, Q.-H. Li, R.-J. Feng, Development of alendronate conjugated poly (lactic-co-glycolic acid)-dextran nanoparticles for active targeting of cisplatin in osteosarcoma, Sci. Rep. 5 (2015) 17387,12 pages.

[10] H. Gheybi, H. Niknejad, A.A. Entezami, Polymer-metal complex nanoparticles-containing cisplatin and amphiphilic block copolymer for anticancer drug delivery, Des. Monomers Polym. 17 (2014) 334-344.

[11] J. Kim, H.-J. Yoon, S. Kim, K. Wang, T. Ishii, Y.-R. Kim, W.-D. Jang, Polymer-metal complex micelles for the combination of sustained drug releasing and photodynamic therapy, J. Mater. Chem. 19 (2009) 4627-4631.

[12] H. Shi, Q. Cheng, S. Yuan, X. Ding, Y. Liu, Human serum albumin conjugated nanoparticles for $\mathrm{pH}$ and redox-responsive delivery of a prodrug of cisplatin Chem. Eur J. 21 (2015) 16547-16554.

[13] A.K.P. Ilaiyaraja, W.S. Beaula, V.V. Kumari, J.S. Lal, C. Arunkumar, G. Anjana, S. Srinivas, A. Ramesh, S.K. Rayala, D. Ponraju, G. Venkatraman, Tumor targeting using polyamidoamine dendrimer-cisplatin nanoparticles functionaized with diglycolamic acid and Herceptin, Eur. J. Pharm. Biopharm. 96 (2015) 255-263.

[14] N. Alam, R.D. Dubey, A. Kumar, M. Koul, N. Sharma, P.R. Sharma, B.K. Chandan, S.K. Singh, G. Singh, P.N. Gupta, Reduced toxicological manifestations of cisplatin following encapsulation in folate grafted albumin nanoparticles, Life Sci. 142 (2015) 76-85.

[15] E.S. Antonarakis, A. Emadi, Ruthenium-based chemotherapeutics: are they ready for prime time? Cancer Chemother. Pharmacol. 66 (2010) 1-9.

[16] J.M. Rademaker-Lakhai, D. van den Bongard, D. Pluim, J.H. Beijnen, J.H.M. Schellens, A phase I and pharmacological study with imidazolium-
transDMSO-imidazole-tetrachlororuthenate, a novel ruthenium anticancer agent, Clin. Cancer Res. 10 (2004) 3717-3727.

[17] C.G. Hartinger, M.A. Jakupec, S. Zorbas-Seifried, M. Groessl, A. Egger, W. Berger, H. Zorbas, P.J. Dyson, B.K. Keppler, KP1019, a new redox-active anticancer agent - preclinical developmentand results of a clinical phase I study in tumor patients, Chem. Biodivers. 5 (2008) 2140-2155.

[18] A. Bergamo, C. Gaiddon, J.H.M. Schellens, J.H. Beijnen, G. Sava, Approaching tumour therapy beyond platinum drugs: status of the art and perspectives of ruthenium drug candidates, J. Inorg. Biochem. 106 (2012) 90-99.

[19] M.I. Webb, C.J. Walsby, Control of ligand-exchange processes and the oxidation state of the antimetastatic Ru(III) complex NAMI-A by interactions with human serum albumin, Dalton Trans. 40 (2011) 1322-1331.

[20] A. Valente, M.H. Garcia, Syntheses of macromolecular ruthenium compounds: a new approach to the search of anticancer drugs, Inorganics 2 (2014) 96-114.

[21] B.M. Blunden, M.H. Stenzel, Incorporating ruthenium into advanced drug delivery carriers - an innovative generation of chemotherapeutics, J. Chem. Technol. Biotechnol. 90 (2015) 1177-1195.

[22] P. Govender, T. Riedel, P.J. Dyson, G.S. Smith, Higher generation cationic N,Nruthenium(II)-ethylene-glycol-derived metallodendrimers: synthesis, characterization and cytotoxicity, J. Organomet. Chem. 799-800 (2015) 38-44.

[23] S. Michlewska, M. Ionov, D. Shcharbin, M. Maroto-Díaz, R.G. Ramirez, F.J. de la Mata, M. Bryszewska, Ruthenium metallodendrimers with anticancer potential in an acute promyelocytic leukemia cell line (HL60), Eur. Polym. J. 87 (2017) 39-47.

[24] A. Pitto-Barry, O. Zava, P.J. Dyson, R. Deschenaux, B. Therrien, Enhancement of cytotoxicity by combining pyrenyl-dendrimers and arene ruthenium metallacages, Inorg. Chem. 51 (2012) 7119-7124.

[25] T.R. Cook, V. Vajpayee, M.H. Lee, P.J. Stang, K.-W. Chi, Biomedical and biochemical applications of self-assembled metallacycles and metallacages, Acc. Chem. Res. 46 (2013) 2464-2474.

[26] I.N. Stepanenko, A. Casini, F. Edafe, M.S. Novak, V.B. Arion, P.J. Dyson, M.A. Jakupec, B.K. Keppler, Conjugation of organoruthenium(II) 3-(1H-benzimidazol-2-yl)pyrazolo[3,4-b]pyridines and indolo[3,2-d]benzazepines to recombinant human serum albumin: a strategy to enhance cytotoxicity in cancer cells, Inorg. Chem. 50 (2011) 12669-12679.

[27] S. Zhao, X. Zhu, C. Cao, J. Sun, J. Liu, Transferrin modified ruthenium nanoparticles with good biocompatibility for photothermal tumor therapy, J. Colloid Interface Sci. 511 (2018) 325-334.

[28] G. Süss-Fink, F.-A. Khan, L. Juillerat-Jeanneret, P.J. Dyson, A.K. Renfrew, Synthesis and anticancer activity of long-chain isonicotinic ester ligandcontaining arene ruthenium complexes and nanoparticles, J. Clus. Sci. 21 (2010) 313-324.

[29] B.M. Blunden, R. Chapman, M. Danial, H. Lu, K.A. Jolliffe, S. Perrier, M.H. Stenzel, Drug conjugation to cyclic peptide-polymer self-assembling nanotubes, Chem. Eur J. 20 (2014) 12745-12749.

[30] B.M. Blunden, H. Lu, M.H. Stenzel, Enhanced delivery of the RAPTA-C macromolecular chemotherapeutic by conjugation to degradable polymeric micelles, Biomacromolecules 14 (2013) 4177-4188.

[31] W. Sun, X. Zeng, S. Wu, Photoresponsive ruthenium-containing polymers: potential polymeric metallodrugs for anticancer Phototherapy, Dalton Trans. 47 (2018) 283.

[32] H. Lu, B.M. Blunden, W. Scarano, M. Lu, M.H. Stenzel, Anti-metastatic effects of RAPTA-C conjugated polymeric micelles on two-dimensional (2D) breast tumor cells and three-dimensional (3D) multicellular tumor spheroids, Acta Biomater. 32 (2016) 68-76.

[33] M. Lu, F. Chen, J.-M. Noy, H. Lu, M.H. Stenzel, Enhanced antimetastatic activity of the ruthenium anticancer drug RAPTA-C delivered in fructose-coated micelle, Macromol. Biosci. 17 (2017) 1600513, 11 pages.

[34] B.M. Blunden, H. Lu, M.H. Stenzel, Enhanced delivery of the RAPTA-C macromolecular chemotherapeutic by conjugation to degradable polymeric micelles, Biomacromolecules 14 (2013) 4177-4188.

[35] W. Sun, S. Li, B. Häupler, J. Liu, S. Jin, W. Steffen, U.S. Schubert, H.-J. Butt, X.J. Liang, S. Wu, An amphiphilic ruthenium polymetallodrug for combined photodynamic therapy and photochemotherapy in vivo, Adv. Mater. 29 (2017) 1603702, 6 pages.

[36] G. Mangiapia, G. D'Errico, L. Simeone, C. Irace, A. Radulescu, A. Di Pascale, A. Colonna, D. Montesarchio, L. Paduano, Ruthenium-based complex nanocarriers for cancer therapy, Biomaterials 33 (2012) 3770-3782.

[37] B. Fischer, P. Heffeter, K. Kryeziu, L. Gille, S.M. Meier, W. Berger, C.R. Kowol, B.K. Keppler, Poly(lactic acid) nanoparticles of the lead anticancer ruthenium compound KP1019 and its surfactant-mediated activation, Dalton Trans. 43 (2014) 1096-1104.

[38] B.M. Blunden, A. Rawal, H. Lu, M.H. Stenzel, Superior chemotherapeutic benefits from the ruthenium-based anti-metastatic drug NAMI-A through conjugation to polymeric micelles, Macromolecules 47 (2014) 1646-1655.

[39] L. Du, X. Yu, Z. Yan-Hui, Z. Xue-Yun, L. Jie, Y. Yong-Guang, Development of NAMI-A-loaded PLGA-mPEG nanoparticles: physicochemical characterization, in vitro drug release and in vivo antitumor efficacy, Chem. Res. Chin. Univ. 27 (2011) 345-349.

[40] A. Valente, M.H. Garcia, F. Marques, Y. Miao, C. Rousseau, P. Zinck, First polymer "ruthenium-cyclopentadienyl" complex as potential anticancer agent, J. Inorg. Biochem. 127 (2013) 79-81.

[41] M. H. Garcia, A. Valente, T. S. F. Morais, A. I. Tomaz, Macromolecular Transition Metal Complexes for Treatment of Cancer and Process for Their Preparation, 
WO 2016/087932.

[42] L. Côrte-Real, B. Karas, P. Gírio, A. Moreno, F. Avecilla, F. Marques, B.T. Buckley, K.R. Cooper, C. Doherty, P. Falson, M.H. Garcia, A. Valente, Unprecedented inhibition of P-gp activity by a novel ruthenium-cyclopentadienyl compound bearing a bipyridine-biotin ligand, Eur. J. Med. Chem. 163 (2019) 853-863.

[43] V. Moreno, M. Font-Bardia, T. Calvet, J. Lorenzo, F.X. Alvilés, M.H. Garcia, T.S. Morais, A. Valente, M.P. Robalo, DNA interaction and cytotoxicity of new ruthenium (II) cyclopentadienyl derivative complexes containing heteroaromatic ligands, J. Inorg. Biochem. 105 (2011) 241-249.

[44] L. Côrte-Real, F. Marques, M.P. Robalo, G. Nogueira, F. Avecilla, F.C. Santos, A.I. Tomaz, M.H. Garcia, A. Valente, The significant role of coligands in novel ruthenium(II)-cyclopentadienyl bipyridine derivatives: ranging from noncytotoxic to highly cytotoxic compounds, J. Inorg. Biochem. 150 (2015) $148-159$.

[45] A.I. Tomaz, T. Jakusch, T.S. Morais, F. Marques, R.F.M. de Almeida, F. Mendes, E.A. Enyedy, I. Santos, J.C. Pessoa, T. Kiss, M.H. Garcia, [RuII( $\eta 5$ C5H5)(bipy)(PPh3)]+, a promising large spectrum antitumor agent: cytotoxic activity and interaction with human serum albumin, J. Inorg. Biochem. 117 (2012) 261-269.

[46] T.S. Morais, F.C. Santos, T.F. Jorge, L. Côrte-Real, P..A. Madeira, F. Marques, M.P. Robalo, A. Matos, I. Santos, M.H. Garcia, New water-soluble ruthenium(II) cytotoxic complex: biological activity and cellular distribution, J. Inorg. Biochem. 130 (2014) 1-14.

[47] L. Côrte-Real, A.P. Matos, I. Alho, T.S. Morais, A.I. Tomaz, M.H. Garcia, I. Santos, M.P. Bicho, F. Marques, Cellular uptake mechanisms of an antitumor ruthenium compound: the endosomal/lysosomal system as a target for anticancer metal-based drugs, Microsc. Microanal. 19 (2013) 1122-1130.

[48] L. Côrte-Real, F. Mendes, J. Coimbra, T.S. Morais, A.I. Tomaz, A. Valente, M.H. Garcia, I. Santos, M. Bicho, F. Marques, Anticancer activity of structurally related ruthenium(II) cyclopentadienyl complexes, J. Biol. Inorg. Chem. 19 (2014) 853-867.

[49] A.M. Rieger, K.L. Nelson, J.D. Konowalchuk, D. Barreda, Modified Annexin V/ propidium iodide apoptosis assay for accurate assessment of cell death, J. Vis. Exp. 50 (2011), e2597, 1-4.

[50] R. Schmadeka, B.E. Harmon, M. Singh, Triple-negative breast carcinoma: current and emerging concepts, Am. J. Clin. Pathol. 141 (2014) 462-477.

[51] S. Liang, X. Peng, X. Li, P. Yang, L. Xie, Y. Li, C. Du, G. Zhang, Silencing of CXCR4 sensitizes triple-negative breast cancer cells to cisplatin, Oncotarget 6 (2015) 1020-1030.

[52] J. Frede, S.P. Fraser, G. Oskay-Özcelik, Y. Hong, I. Braicu, J. Sehouli, H. Gabra, M.B.A. Djamgoz, Ovarian cancer: ion channel and aquaporin expression as novel targets of clinical potential, Eur. J. Cancer 49 (2013) 2331-2344.

[53] H. Burger, W.J. Loos, K. Eechoute, J. Verweij, R.H. Mathijssen, E.A. Wiemer, Drug transporters of platinum-based anticancer agents and their clinical significance, Drug Resist. Updates 14 (2011) 22-34.

[54] R. Januchowski, P. Zawierucha, M. Rucinski, M. Andrzejewska, K. Wojtowicz, M. Nowicki, M. Zabel, Drug transporter expression profiling in chemoresistant variants of the A2780 ovarian cancer cell line, Biomed. Pharmacother. 68 (2014) 447-453.

[55] R. Januchowski, K. Wojtowicz, P. Sujka-Kordowska, M. Andrzejewska, M. Zabel, MDR gene expression analysis of six drug-resistant ovarian cancer cell lines, BioMed Res. Int. (2013), 241763, 10 pages.

[56] K. Taniguchi, M. Wada, K. Kohno, T. Nakamura, T. Kawabe, M. Kawakami, K. Kagotani, K. Okumura, S.-i. Akiyama, M. Kuwano, A human canalicular multispecific organic anion transporter (cMOAT) gene is overexpressed in cisplatin-resistant human cancer cell lines with decreased drug accumulation, Cancer Res. 56 (1996) 4124-4129.

[57] J.J. Ma, B.L. Chen, X.Y. Xin, Inhibition of multi-drug resistance of ovarian carcinoma by small interfering RNA targeting to MRP2 gene, Arch. Gynecol. Obstet. 279 (2009) 149-157.

[58] V. Materna, A. Stege, P. Surowiak, A. Priebsch, H. Lage, RNA interferencetriggered reversal of $\mathrm{ABCC} 2$-dependent cisplatin resistance in human cancer cells, Biochem. Biophys. Res. Commun. 348 (2006) 153-157.

[59] E. Baiceanu, K.A. Nguyen, L. Gonzalez-Lobato, R. Nasr, H. Baubichon-Cortay, F. Loghin, M. Le Borgne, L. Chow, A. Boumendjel, M. Peuchmaur, P. Falson, 2 Indolylmethylenebenzofuranones as first effective inhibitors of ABCC2, Eur. J Med. Chem. 122 (2016) 408-418.

[60] E. Comsa, K.A. Nguyen, F. Loghin, A. Boumendjel, M. Peuchmaur, T. Andrieu, P. Falson, Ovarian cancer cells cisplatin sensitization agents selected by mass cytometry target ABCC2 inhibition, Future Med. Chem. 10 (2018) 1349-1360.

[61] K.L. Brouwer, D. Keppler, K.A. Hoffmaster, D. A.J. Bow, Y. Cheng Y. Lai, J.E. Palm, B. Stieger, R. Evers, In vitro methods to support transporter evaluation in drug discovery and development, Clin. Pharmacol. Ther. 94 (2013) 95-112.

[62] R. Prasad, M.K. Rawal, Efflux pump proteins in antifungal resistance, Front. Pharmacol. 5 (2014) 1-13. Article 202.

[63] J.J. Vicente, L. Wordeman, Mitosis, microtubule dynamics and the evolution of kinesins, Exp. Cell Res. 334 (2015) 61-69.

[64] D. Whitley, S.P. Goldberg, W.D. Jordan, Heat shock proteins: a review of the molecular chaperones, J. Vasc. Surg. 29 (1999) 748-751.

65] C. Dumontet, M.A. Jordan, Microtubule-binding agents: a dynamic field of cancer therapeutics, Nat. Rev. Drug Discov. 9 (2010) 790-803.

[66] A. Gandalovičová, D. Rosel, M. Fernandes, P. Veselý, P. Heneberg, V. Čermák, L. Petruželka, S. Kumar, V. Sanz-Moreno, J. Brábek, Migrastatics - antimetastatic and anti-invasion drugs: promises and challenges, Trends Canc. 3 (2017) 391-406.

[67] S. Gama, F. Mendes, T. Esteves, F. Marques, A. Matos, J. Rino, J. Coimbra, M. Ravera, E. Gabano, I. Santos, A. Paulo, Synthesis and biological studies of pyrazolyl-diamine $\mathrm{Pt}(\mathrm{II})$ complexes containing polyaromatic DNA-binding groups, Chembiochem 13 (2012) 2352-2362.

[68] Q. Chang, O.I. Ornatsky, C.J. Koch, N. Chaudary, D.T. Marie-Egyptienne R.P. Hill, S.D. Tanner, D.W. Hedley, Single-cell measurement of the uptake, intratumoral distribution and cell cycle effects of cisplatin using mass cytometry, Int. J. Cancer 136 (2015) 1202-1209.

[69] K.E. Diggins, P.B. Ferrell Jr., J.M. Irish, Methods for discovery and characterization of cell subsets in high dimensional mass cytometry data, Methods 82 (2015) 55-63.

[70] R. Evers, M. Kool, vL. Deemter, H. Janssen, J. Calafat, L.C.J.M. Oomen, C.C. Paulusma, R.P.J.O. Elferink, F. Baas, A.H. Schinkel, P. Borst, Drug export activity of the human canalicular multispecific organic anion transporter in polarized kidney MDCK cells expressing cMOAT (MRP2) cDNA, J. Clin. Invest. 101 (1998) 1310-1319.

[71] A. Keller, A.I. Nesvizhskii, E. Kolker, R. Aebersold, Empirical statistical model to estimate the accuracy of peptide identifications made by MS/MS and database search, Anal. Chem. 74 (2002) 5383-5392.

[72] A.I. Nesvizhskii, A. Keller, E. Kolker, R. Aebersold, A statistical model for identifying proteins by tandem mass spectrometry, Anal. Chem. 75 (2003) 4646-4658.

[73] P.D. homas, M.J. Campbell, A. Kejariwal, H. Mi, B. Karlak, R. Daverman, K. Diemer, A. Muruganujan, A. Narechania, PANTHER: a library of protein families and subfamilies indexed by function, Genome Res. 13 (2003) 2129-2141.

[74] D. Szklarczyk, J.H. Morris, H. Cook, M. Kuhn, S. Wyder, M. Simonovic A. Santos, N.T. Doncheva, A. Roth, P. Bork, L.J. Jensen, C. von Mering, The STRING database in 2017: quality-controlled protein-protein association networks, made broadly accessible, Nucleic Acids Res. 45 (2017) 362-368. 